\title{
Analysis of 60 pharmaceuticals and personal care products in sewage sludge by ultra-high performance liquid chromatography and tandem mass spectroscopy
}

\author{
N. Pérez-Lemus ${ }^{\text {a,b,c }}$, R. López-Serna ${ }^{\text {a,c }}$, S.I. Pérez-Elvira ${ }^{\text {b,c }}$, E. Barrado ${ }^{\text {a,c,* }}$

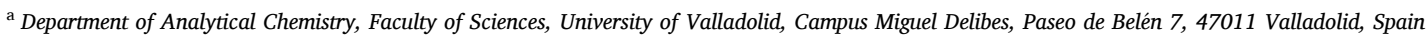 \\ ${ }^{\mathrm{b}}$ Department of Chemical Engineering and Environmental Technology, School of Industrial Engineering, University of Valladolid, Dr. Mergelina, s/n, 47011 Valladolid, \\ Spain \\ ${ }^{\mathrm{c}}$ Institute of Sustainable Processes, Dr. Mergelina s/n, 47011 Valladolid, Spain
}

\section{A R T I C L E I N F O}

\section{Keywords:}

LC-MS/MS

Compounds of emerging concern (CECs)

Target analysis

High throughput

Green chemistry

Triple quadrupole

\begin{abstract}
A B S T R A C T
This paper presents a comparison of three different analytical proposals for the determination of 60 pharmaceuticals and personal care products (PPCPs) in solid urban sewage sludge. Two fast sample pretreatments, i.e., online solid-phase-extraction (online SPE) and direct injection (DI), were tested against the conventional offline solid phase extraction (offline SPE). In all cases, subsequently, extracts underwent ultra-high-performance-liquid chromatography coupled to tandem-mass-spectrometry (UHPLC-MS/MS), simultaneously operating in both positive and negative electrospray ionization (ESI) mode. In addition, as solid matrices, clean-up steps were necessarily preceded by ultra-sound-assisted extraction (UAE) in all cases. Matrix-matched quantification was combined with internal standard providing high reliability to all three approaches. Best performance was observed for the fully automatized and non-pretreated DI method, showing limits of detection below $30 \mathrm{ng} \mathrm{g}^{-1}$ for many of the target compounds, and recoveries between 80 and $120 \%$. Finally, the best working method was validated and applied to the analysis of PPCPs in different dewatered digested sludge samples from the wastewater treatment plant (WWTP) in Valladolid (Spain). Acetaminophen was found at concentrations above 1,000 $\mathrm{ng} \mathrm{g}^{-1}$.
\end{abstract}

\section{Introduction}

Pharmaceuticals, used to treat human and animal diseases, and personal care products include different classes of organic chemicals, which are used especially for a better quality of daily life. Once they reach the environment become pollutants that fall into the category of compounds of emerging concern (CECs) [1-3].

Wastewater treatment plants (WWTPs) serve to treat wastewater, reducing the adverse effects of various pollutants on the environment and maintaining a good quality of life for all living beings. However, they are designed to remove solid materials and reduce levels of metals, bacteria, and other pathogens [4], but are not efficient for the removal of PPCPs, so effluents discharged directly into aquatic systems may contain significant amounts of these substances [5]. The use of analgesics and anti-inflammatory drugs is high in southern European countries, such as Spain [6], and salicylic acid and ibuprofen are the compounds with the highest concentrations found in wastewater and sludge [7].

In recent years, there has been a boom in the development of analytical methods for the determination of PPCPs in environmental matrices such as sewage sludge. A literature review by Pérez-Lemus et al., [8] reported that LC-MS/MS is the main technique used for the analysis of PPCPs in environmental matrices because it is highly versatile, sensitive and selective [9]. Regarding sample pre-treatment, UAE is mostly used when PPCPs are determined in solid environmental matrices such as sewage sludge. This technique is easy and fast in preparation, and, in addition, reduces the usual requirements of high organic solvent volumes [8]. As this extraction step is not very selective, it is conventionally followed by a clean-up protocol. To this end, SPE, onto disposable cartridges in a manifold, is the technique most commonly used. It requires the subsequent cartridge elution, solvent evaporation and extract reconstitution before instrumental analysis [10-11]. All these steps are time consuming -they usually take two full

\footnotetext{
Abbreviations: LC-MS/MS, Liquid Chromatography coupled to tandem-Mass-Spectrometry; CECs, Compounds of emerging concern.

* Corresponding author.
} 
working days-, and are a source of error introduction as they typically entail low automation as well as analyst manipulation and exposure to toxic chemicals. In addition, large quantities of disposable material and organic solvents are employed. In the last years, alternatives have been developed which instrumentalist SPE and even couple it to the chromatographic section [12-17]. However, their implementation in the routine analysis labs is still scarce. Even less has been explored regarding the possibility of relaying all the selectivity needed after the extraction step to the chromatographic section that is to dispense with the clean-up step by SPE [18-20].

The main objective of this study is to compare the performance of three analytical approaches in the determination of 60 PPCPs of several classes (analgesics/anti-inflammatory, antibiotics, lipid regulators, psychiatric and cardiovascular drugs, hormones, preservatives, surfactants, anti-parasites, plasticisers, triazine herbicides and antimicrobials) in sewage sludge. All of them included UAE and LC-MS/MS, in an attempt to represent most of the current methodologies. Two fast pretreatments, i.e., a fully automatized SPE online coupled to LC-MS/MS (online SPE), and a direct injection of the UAE extract with no prior clean-up (DI) were tested against the conventional manual SPE-extract reconstitution clean-up protocol (offline SPE).

To the best of our knowledge, this is the first time the performance of sewage-sludge-extracts DI into the LC-MS/MS has been assessed. Novel is also the comparison of these two fast approaches, -online SPE and DIwith the conventional offline SPE clean-up which entails a real bottleneck in the throughput of this type of analytical methods. Pros and limitations of each proposal have been discussed. The best working methodology was validated and applied to the analysis of PPCPs in different dewatered digested sludge samples from the WWTP in Valladolid (Spain).

\section{Material and methods}

\subsection{Standards and reagents}

The standards for all PPCPs (Table S1 and List S1 as Supplementary Material Data) were of high purity grade. Individual stock solutions at $1,000 \mathrm{mg} \mathrm{L}^{-1}$ for most PPCPs standards were prepared in methanol $(\mathrm{MeOH})$. PPCPs such as danofloxacin, enrofloxacin, marbofloxacin, ciprofloxacin, ofloxacin, levofloxacin, and norfloxacin were prepared in $0.2 \%$ hydrochloric acid $(\mathrm{HCl}) \mathrm{MeOH} / \mathrm{MilliQ}^{\circledR}$ water $(1: 1)$ and apramycin in MilliQ ${ }^{\circledR}$ water. From them, two mix stock solutions with 33 and 27 compounds, respectively, were prepared in $\mathrm{MeOH}$ at $20 \mathrm{mg} \mathrm{L}^{-1}$. Subsequently, serial dilutions $(2,0.5,0.05,0.005) \mathrm{mg} \mathrm{L}^{-1}$ in $\mathrm{MeOH}$ contained all the analytes. All solutions were immediately stored at $-80{ }^{\circ} \mathrm{C}$ in darkness until use in the analysis. Sixteen internal standards, such as the isotopically labelled sulfadiazine-d4, sulfadimidine-d4, ciprofloxacin$\mathrm{d} 8$, sulfamethoxazole-d4, danofloxacin-d3, enrofloxacin-d5, rac ibuprofen-d3, rac naproxen-d3, diclofenac-d4, salicylic acid-d4, clofibric acid-d4, methyl-d4-paraben, ethyl-d5-paraben, propyl-d7-paraben, triclosan-d3, bisphenol A-d8 (LGC Standards (Barcelona, Spain) (Table S1), were used. Individual and a mixture of isotopically labelled internal standards were prepared in $\mathrm{MeOH}$ as well as its corresponding serial dilutions $\left(2,0.5,0.05\right.$, and $\left.0.005 \mathrm{mg} \mathrm{L}^{-1}\right)$. All of them were also stored at $-80{ }^{\circ} \mathrm{C}$ in darkness.

High purity solvents, i.e., LC-MS-grade $\mathrm{MeOH}$, LC-MS-grade acetonitrile (ACN) and 98\%-purity formic acid (FA), were provided by Labbox (Madrid, Spain). Ethylenediaminetetraacetic acid (EDTA), with 99\% purity, and aluminium oxide $\left(\mathrm{Al}_{2} \mathrm{O}_{3}\right)$ were purchased to Sigma-Aldrich (Madrid, Spain). Concentrated (37\%) $\mathrm{HCl}$ and sodium hydroxide $(98 \%$ purity) were supplied by Panreac (Barcelona, Spain). Oasis HLB (60 mg, $3 \mathrm{~mL}$ ) SPE cartridges from Waters (Barcelona, Spain). All aqueous solutions were prepared in deionised water with a resistance of not $<18$ $\mathrm{M} \Omega \mathrm{cm}$. Nitrogen $\left(\mathrm{N}_{2}\right)$, with $99.999 \%$ purity, was provided by Abelló Linde S.A. (Madrid, Spain).

\subsection{Sewage sludge analytical methodology}

\subsubsection{Sample collection and conservation}

Sludge samples were collected from the municipal WWTP in Valladolid (Spain). It serves a population of approximately 350,000 inhabitants and treats around $101,000 \mathrm{~m}^{3} \mathrm{day}^{-1}$ of wastewater. In addition, it generates approximately $9,600 \mathrm{~m}^{3}$ day $^{-1}$ of biogas from the digestion of $2,500 \mathrm{~m}^{3}$ day $^{-1}$ of sludge. Activated sludge process is the secondary treatment taking place and responsible of the removal of most part of the macro-pollutants present in the urban wastewater. The surplus biological sludge generated during this aerobic treatment is mixed with the primary sludge and fed to the anaerobic digester. The digestion process considerably reduces the total mass of solids, destroys pathogens, and facilitates dewatering or drying of the sludge. The digested sludge, often called as biosolid, has the appearance and characteristics of a rich potting soil and is dewatered before disposal. The dewatered sludge (DS), which was selected as the matrix for this study, still contains a significant amount of water (up to $80 \%$ ) but, even at this moisture content, the sludge no longer behaves as a liquid and can be handled as a solid material, making it easier to handle and less expensive to transport

DS samples were collected in high density polyethylene drums with polypropylene screw caps and immediately transported to the laboratory at $4{ }^{\circ} \mathrm{C}$ in darkness, where they were stored at $-20^{\circ} \mathrm{C}$ in darkness. Once they were fully frozen, they were freeze-dried, then, back to store at $-20{ }^{\circ} \mathrm{C}$ in darkness until analysis.

\subsubsection{Offline SPE proposal methodology}

Sample pre-treatment for the offline SPE methodological version was based on Argüeso-Mata et al., 2021 [21] and Perez-Lemus et al., 2020 [12], with further optimization to fully adapt the methodology to the matrices and analytes of the present study. Hence, 1) An exact amount of freeze-dried DS $(\sim 0.3 \mathrm{~g})$ was placed in a plastic centrifuge tube $(50 \mathrm{~mL})$, spiked with $200 \mu \mathrm{L}$ of a methanolic solution containing all the isotopically labelled internal standards at $0.5 \mathrm{mg} \mathrm{L}^{-1}$, and then, homogenized. The mixture was, then, let it settle in darkness overnight in the extraction hood for solvent evaporation and internal standard fixation. 2) Subsequently, the sample underwent UAE in a Sonorex Digitec $160 \mathrm{~W}$ $35 \mathrm{kHz}$ ultrasonic bath (Navarra, Spain) for $30 \mathrm{~min}$ at $25^{\circ} \mathrm{C}$ to assist for the desorption and extraction of the analytes. With this purpose, twelve millilitres of a $\mathrm{MeOH} / \mathrm{MilliQ}{ }^{\circledR}$ water mixture, 5:95 (v/v) and $\mathrm{pH}$ adjusted to 9 was added as extracting solvent. At this $\mathrm{pH}$, most of the target analytes were expected to be present in their ionic form (Table S1) encouraging their desorption and extraction towards the extracting solvent. Additionally, one hundred milligrams of activated alumina $\left(\mathrm{Al}_{2} \mathrm{O}_{3}\right.$, dried at $105^{\circ} \mathrm{C}$ for $\left.48 \mathrm{~h}\right)$ were added to the resulting suspension too, for matrix in-situ clean-up during the UAE. After the UAE, the extract was centrifuged for $10 \mathrm{~min}$ at $10,000 \mathrm{rpm}$ and $10 \mathrm{~mL}$ of the supernatant were collected with a glass pipette. Then, another fresh 12 $\mathrm{mL}$ aliquot of the same extraction solvent was added, and a new extraction cycle was carried out. 3) The pooled supernatant $(20 \mathrm{~mL})$ was filtered through a $0.45-\mu \mathrm{m}$ polytetrafluoroethylene (PTFE) syringe filter and placed in a $100 \mathrm{~mL}$ glass bottle. 4) A $2 \mathrm{~mL}$ aliquot of a 5\% EDTA solution and $80 \mathrm{~mL}$ of desionized water were added too. The resulting solution was $\mathrm{pH} 3$ adjusted to increase the analyte lipophilia by shifting their acid-base equilibrium towards neutral molecules in preparation for the offline SPE clean-up step. SPE was performed onto Oasis HLB SPE cartridges which were previously activated and conditioned with $3 \mathrm{~mL}$ $\mathrm{MeOH}$ and desionized water, respectively. After extraction (assisted by vacuum in a manifold) was carried out, cartridges were rinsed with $3 \mathrm{~mL}$ of a $5 \% \mathrm{MeOH}$ solution, and then dried for 20-30 min. Cartridges were stored at $-20^{\circ} \mathrm{C}$ in darkness if not immediately eluted. For the elution, 2 $\times 3 \mathrm{~mL}$ of ACN were used, with no vacuum assistance. Extracts were then dried under a $\mathrm{N}_{2}$ stream using an Organomation N-EVAP 11,250 evaporator and stored at $-20{ }^{\circ} \mathrm{C}$ in darkness until the instrumental analysis by LC-MS/MS. Then, the extracts were reconstituted with 1.0 
$\mathrm{mL}$ of $0.1 \% \mathrm{FA}$ in $\mathrm{MeOH} /$ water mixture (5:95, v/v), as it constitute the mix of mobile phases at initial conditions in the LC gradient used during the chromatographic gradient described below. Extracts were filtered through a PTFE 0.22- $\mu \mathrm{m}$ syringe filter before instrumental injection. 5) The instrumental LC-MS/MS analysis was performed using a UHPLC Sciex Exion system connected to a Sciex 6500 + triple-quadrupole mass spectrometer from Sciex equipped with an ESI source operated in both positive and negative mode in the same run. Chromatographic separation was achieved by a Phenomenex reversed-phase column Kinetex EVO C18 $(50 \times 2.1 \mathrm{~mm}, 1.7 \mu \mathrm{m})$, which was temperature-controlled at $40{ }^{\circ} \mathrm{C}$ along the entire chromatogram. The gradient run at $500 \mu \mathrm{L} \mathrm{min}-1$ with $0.1 \% \mathrm{FA}(\mathrm{v} / \mathrm{v})$ in water and $0.1 \% \mathrm{FA}$ in $\mathrm{MeOH}$ as mobile phases starting with $5 \%$ of the organic phase for $1 \mathrm{~min}$ and then increasing to $95 \%$ in $2 \mathrm{~min}$, held at $95 \%$ for $3 \mathrm{~min}$, and finally returning to the initial conditions, which were kept for $4 \mathrm{~min}$. The total run time for each injection was $10 \mathrm{~min}$. Injection volume was set at $10 \mu \mathrm{L}$. Mass spectrometry acquisition was performed in selected-reaction monitoring (SRM) mode, recording the transitions between the precursor ion and the two most abundant product ions for each target analyte, thus achieving four identification points per compound (2002/657/EC) [22]. Table S2 shows the specific details of the UHPLC-MS/MS conditions. In addition, ESI operational settings were: capillary voltage, $4500 \mathrm{~V}$; capillary temperature, $400{ }^{\circ} \mathrm{C}$; both gas 1 and 2,45 psi. Data acquisition and evaluation were performed by SciexOS software.

\subsubsection{Online SPE proposed methodology}

Protocol for the online SPE methodological approach was identical to the one described in section 2.2.2, except for the step 4) which was substituted by the addition of $400 \mu \mathrm{L}$ of $5 \%$ EDTA to the extract. The resulting solution was $\mathrm{pH} 3$ adjusted and then filtered through a $0.45-\mu \mathrm{m}$ PTFE syringe filter. The filtrate underwent instrumental online SPE coupled to the LC-MS/MS method described above. Four injection volumes, i.e., 50, 100, 200 and $300 \mu \mathrm{L}$, were tested. A Strata-X $25 \mathrm{um} 20 \times$ $2.0 \mathrm{~mm}$ online reusable cartridge by Phenomenex was used. Extract was conveyed to the cartridge by a $5 \% \mathrm{MeOH}$ solvent at a flow rate of $1 \mathrm{~mL}$ $\min ^{-1}$ for $1 \mathrm{~min}$. In this conditions, extract was fully seeded in the cartridge and rinsed. Subsequently, UHPLC gradient described above would elute backwards the cartridge towards the analytical column.

\subsubsection{DI proposed methodology}

Protocol for the DI methodological option was identical to the one described in section 2.2.2, except for the steps 3 ) and 4) which were substituted by $\mathrm{pH} 3$ adjusted and then a filtration through $0.22-\mu \mathrm{m}$ with a PTFE syringe filter. No SPE clean-up was taking place, and thus, no EDTA was added. Hence, extracts were directly injected in the LC-MS/ MS. Four injection volumes, i.e., 50, 100, 200 and $300 \mu \mathrm{L}$, were tested.

\section{Results and discussion}

\subsection{Injection volume optimization in online SPE and DI methodologies}

In this study, the injection volume (Vinj) was optimized to achieve high resolution and reproducibility in chromatographic analysis as it has a significant effect on peak shape and retention time. Four injection volumes, i.e., 50, 100, 200 and $300 \mu \mathrm{L}$, were tested for each proposed methodology. If the linear range is sufficient and the peak shape is good, the Vinj selected will be the one that provides the highest number of compounds with a Method Limit of Quantification (MLQ) $<70 \mathrm{ng} \mathrm{g}^{-1}$ (Fig. 1). The calibration curves acquired were linear with $\mathrm{R}^{2}$ greater than 0.99 within the indicated concentration range for all the contaminants of interest. Therefore, volume of $100 \mu \mathrm{L}$ was found to be the most appropriate for the online SPE and DI methodologies.

After data evaluation, some initial PPCPs proved to be unsuitable for analysis by the different analytical methods at any Vinj as they showed a very weak response or even no response at all. These PPCPs included antibiotics such as (oxytetracycline, doxycycline, tetracycline, among others), hormones ( $\beta$-estradiol, 17- $\alpha$-ethinylestradiol), and surfactants (4-tert-octylphenol and 4-nonylphenol) or others such as bisphenol A. In total 16 initial target compounds were ruled out.

\subsection{Performance comparison for the three methodological proposals}

The analysis time for each methodological approach is different. The protocol for the offline SPE methodology took much more time than for the other two approaches. For the three methodological proposals, the first three steps of the sample pre-treatment mentioned in section 2.2.2 were performed in a day. However, offline SPE was performed for two days before LC-MS/MS analysis and the total run time for each injection was $10 \mathrm{~min}$. On the other hand, online SPE was performed for $2 \mathrm{~min}$,

A)

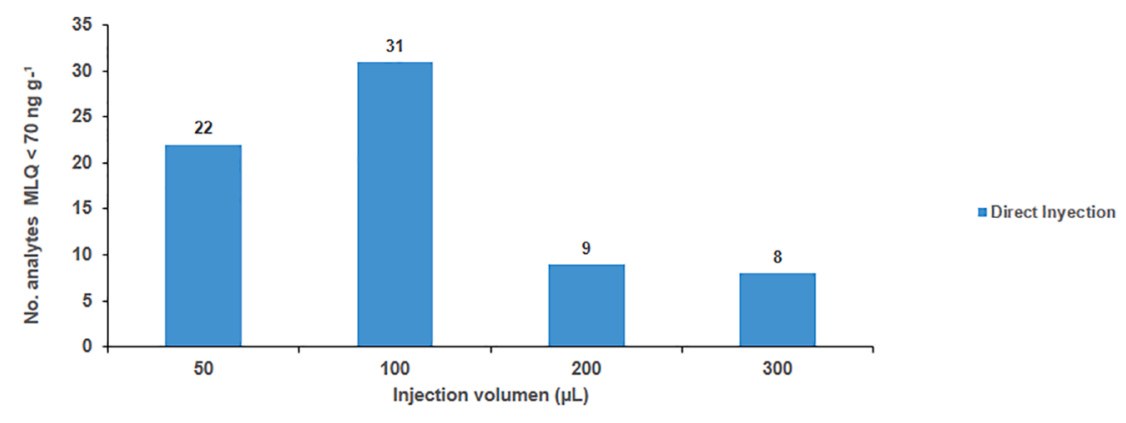

A)

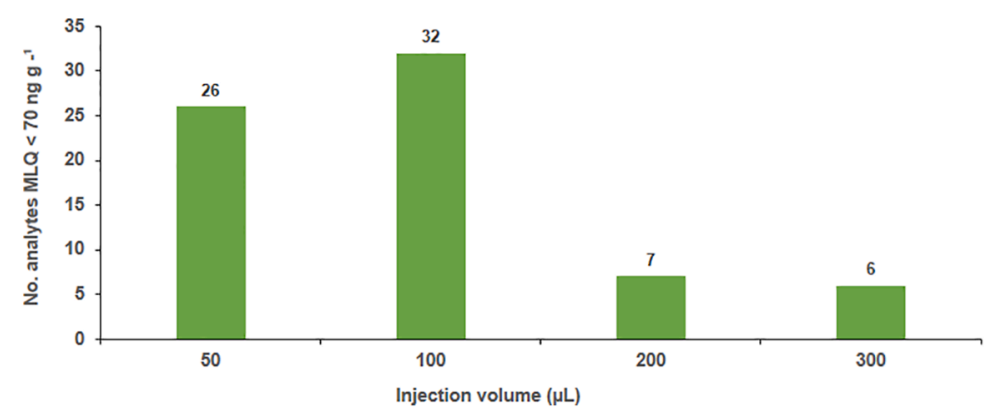

Fig. 1. No of analytes with MLQs below $70 \mathrm{ng} \mathrm{g}^{-1}$ in different injection volumes tested for each methodological proposal A) ONline SPE and B) DI. 
based on the protocol mentioned in section 2.2.3, before LC-MS/MS analysis and for both online SPE and DI proposals, the total run time for each injection was also $10 \mathrm{~min}$. Finally, the alternative methodologies to the conventional offline SPE protocol are faster methods to prepare and analyse a larger amount of samples per unit time.

Theoretical nanograms introduced in each injection for each sample on each point of the calibration curve were calculated, taking into account the optimized Vinj of each analytical proposal. The values calculated are shown in Table S3 and they indicated that the offline SPE samples introduced, at least theoretically, a higher amount of analytes into the chromatographic system. In contrast, the online SPE and DI samples introduced the smallest amount of analytes. Fig. 2 shows a representation of the theoretical nanograms introduced into each injection of each point of calibration curve for clofibric acid (isotopically labelled clofibric acid-d4 internal standard) and apramycin. The results reported a better slope of the calibration curve for DI samples than for the other two proposals. In addition, recoveries for the DI approach should be somewhat higher than for the online SPE approach, not performing a clean-up stage prior to samples analysis. However, the results showed similar values and this may be due to the fact that the matrix effect in the online SPE samples is reduced thanks to the clean-up stage mentioned above, generating better recoveries and more signal from the analytes. Calculated recoveries revealed satisfactory values between $80 \%$ and $110 \%$, with a Relative Standard Deviation (RSD) lower than $18 \%$ for almost all compounds of interest in DI samples. In contrast, recovery values between $70 \%$ and $120 \%$, with a RSD $<20 \%$ and recoveries between 60 and $105 \%$ with a RSD $<23 \%$ were observed for most of the analytes of interest in the online and offline SPE samples, respectively.

MLQs were experimentally determined for target compounds in each methodological proposal. DI samples provided MLQs lower than $70 \mathrm{ng}$ $\mathrm{g}^{-1}$ for $70 \%$ of the analytes in dewatered digested sludge. In contrast, MLQs below $70 \mathrm{ng} \mathrm{g}^{-1}$ were obtained for $73 \%$ and $43 \%$ of studied compounds in online and offline SPE samples, respectively (Fig. 3). Based on sensitivity (and linear range and peak shape), the best approach for the determination of PPCPs in dewatered digested sludge is the DI proposal methodology.

The disadvantage of online SPE is chromatography. Offline SPE and DI methodologies provided chromatograms with similar skylines. Retention times and peak shape were similar. In these versions, the compounds over $5 \mathrm{~min}$, in particular between $0.72 \mathrm{~min}$ (metronidazole) and the $5.12 \mathrm{~min}$ (progesterone). In addition, the peak width range around $0.18 \mathrm{~min}$ with a few exceptions. However, in the chromatograms obtained with online SPE, all the compounds agglomerated and eluted within $2.5 \mathrm{~min}$. The clumping in the elution of the compounds may hint at the clumping of the matrix elution, which could be related to an increase in the matrix effect. However, the clean-up stage carried out by online SPE seems to compensate. In addition, the average peak width is approximately triple in online SPE compared to the other two methods, which could have a negative effect on sensitivity, but it is not observed, so the matrix elimination effect by online SPE seems to compensate or better recovery with respect to offline SPE. Fig. 4 shows an Exchange Ion Chromatogram with the first transition of some compounds, including the first and last analyte to elute, for each proposed methodology.

Finally, a review of the data obtained from the method quality parameters mentioned above concluded that the most suitable method for the analysis of the PPCPs of interest (Table S1) corresponded to a DI in LC-MS/MS. This proposed method showed the best results for linearity range, accuracy, precision, Method Limits of Detection (MLDs) and MLQs. This is despite the fact that the lowest amounts of theoretical nanograms were introduced in each injection of each sample as are presented in Table S3. This resulting methodology stands out for its environmental and analyst safety and short time consumption. In addition, it allows to investigate the fate of a large number of CECs in sludge matrices.

\section{Best working method validation and applications}

\subsection{DI methodology validation}

Validation parameters (accuracy, precision, linearity range, MLD and MLQ) were determined for all target compounds contained in the analytical method.

Quantification method was based on peak areas and performed by both internal standard and matrix-matched approaches in dewatered digested sludge. Each test was performed in duplicated and two significant concentration levels of $333 \mathrm{ng} \mathrm{g}^{-1}$ and $1333 \mathrm{ng} \mathrm{g}^{-1}$ were added. Seven-point calibration curves were generated using linear regression analysis covering the range from 2 to $13333 \mathrm{ng} \mathrm{g}^{-1}$ for all target analytes. Linearity was qualified by the linear correlation coefficient $\left(\mathrm{R}^{2}\right)$,

A)
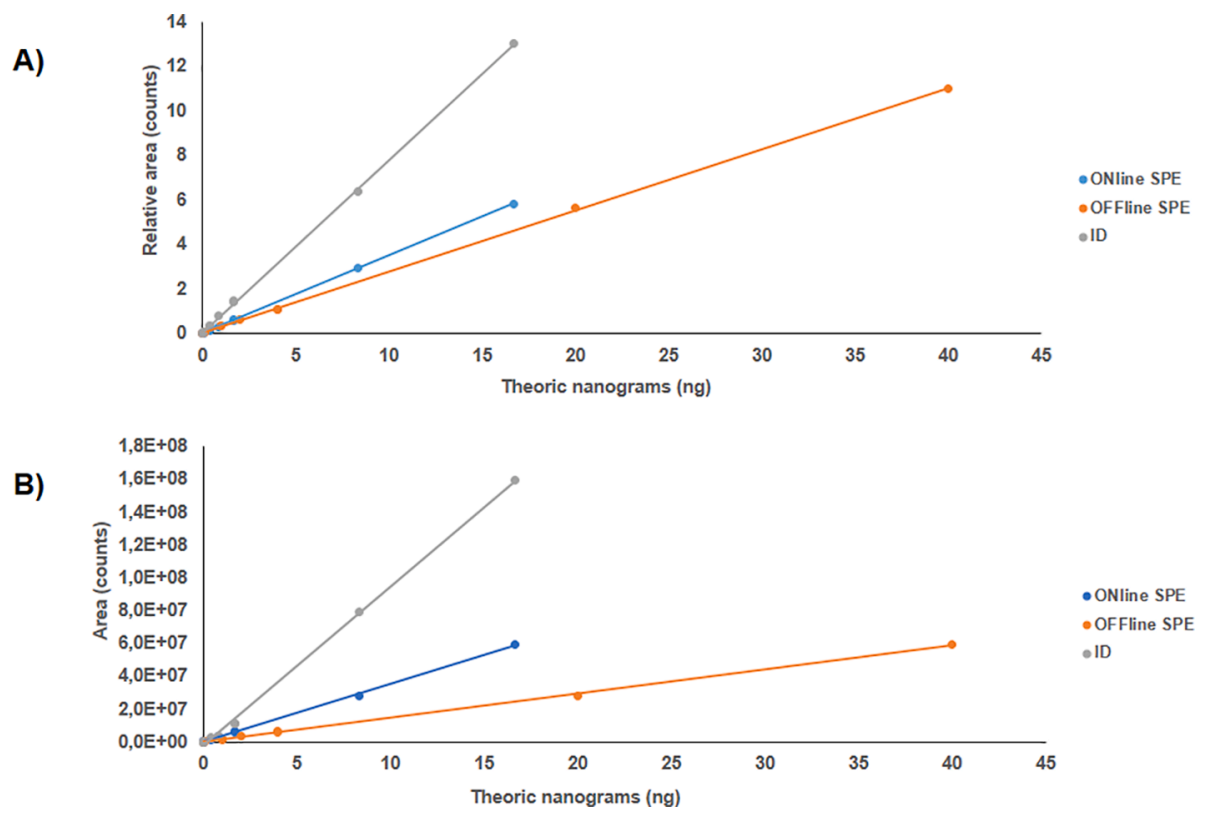

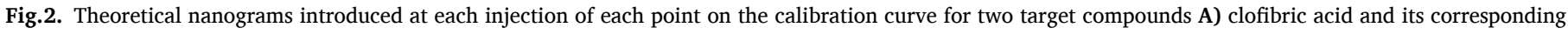
isotopically labelled clofibric acid-d4 internal standard and B) apramycin. 
a. MLQs ng g- ${ }^{-1}$ d.w for ONline SPE

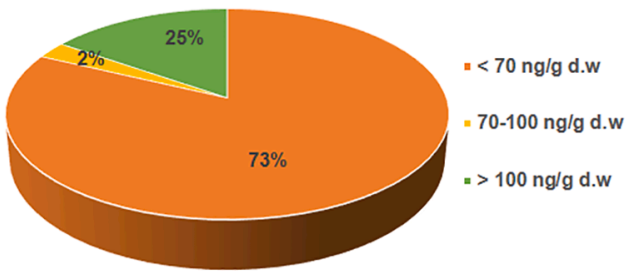

b. MLQs ng g- ${ }^{-1}$ d.w for DI

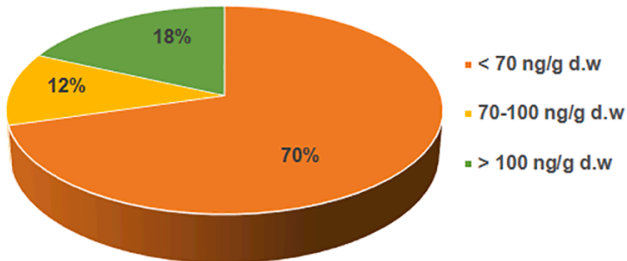

c. MLQs ng g- ${ }^{1}$ d.w for OFFline SPE

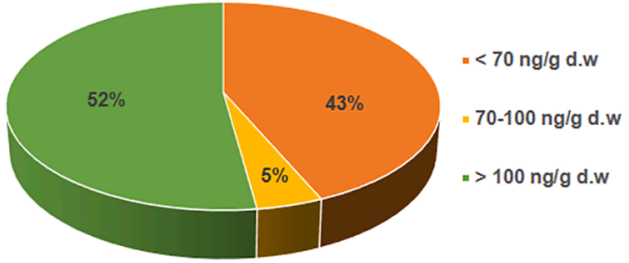

Fig. 3. Distribution of MLQs ng $g^{-1}$ d.w for each proposed methodology a. ONline SPE b. DI and c. OFFline SPE.
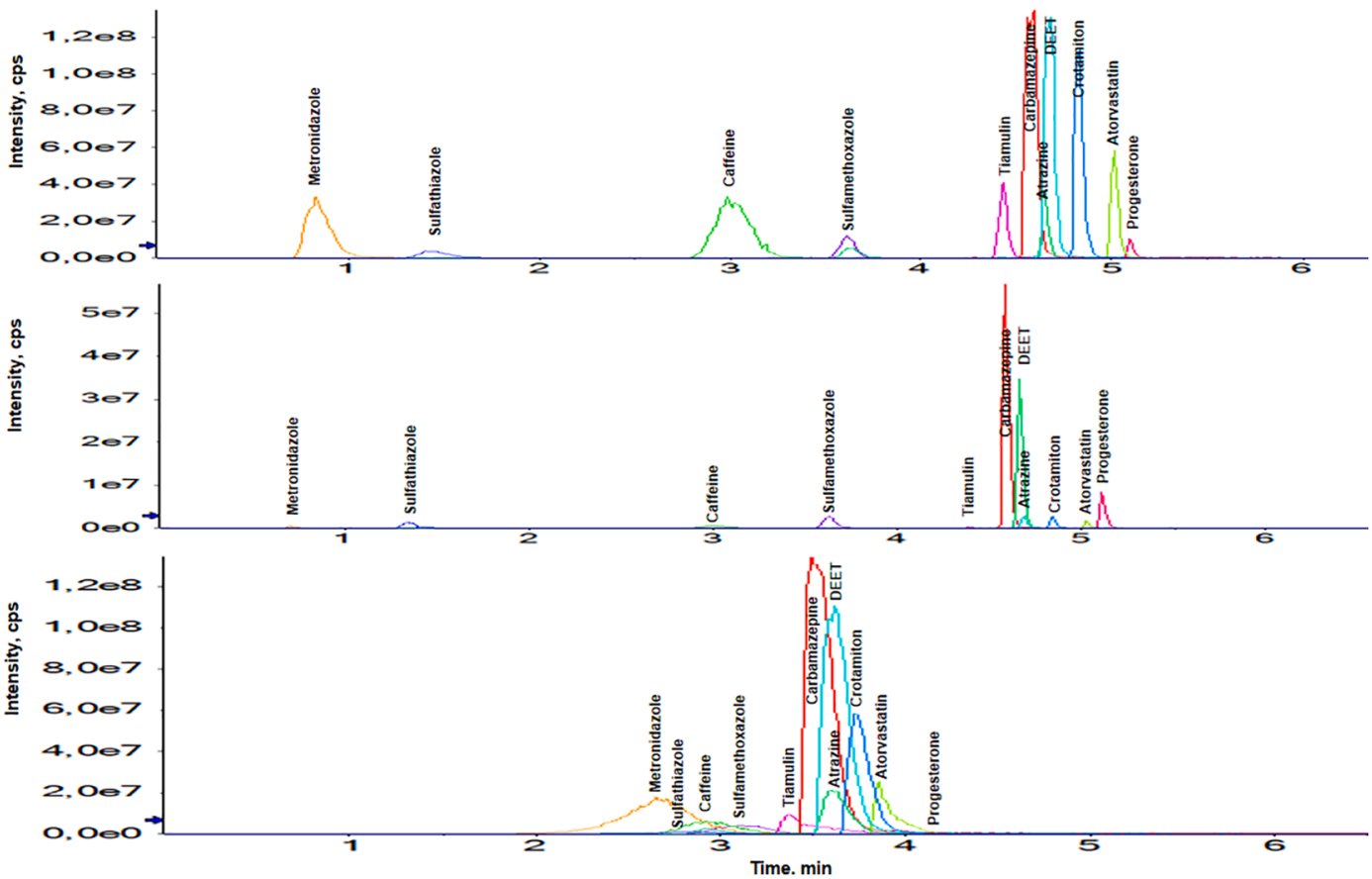

Fig. 4. An Extracted Ion Chromatogram of some PPCPs from a dewatered digested sludge spiked to 13333 ng $\mathrm{g}^{-1}$ and analysed by DI in LC-MS/MS.

with $\mathrm{R}^{2}$ greater than 0.99 , for all the compounds within the indicated concentration range. The main quality parameters for developed method are summarized in Table 1.

In our specific case, method accuracy was expressed as \% recovery and evaluated in samples spiked at two concentration levels (i.e., 333 and $1333 \mathrm{ng} \mathrm{g}^{-1}$ ) for sludge samples. The observed recoveries were in the range $80-110 \%$ for most of cases. The values obtained were successful and very similar to those reported in other studies for the analysis of PPCPs in sewage sludge [23,24].

To ensure correct method precision, \%RSD of the area observed for analogous samples prepared in duplicated with the developed method was calculated. A $\%$ RSD below $18 \%$ was observed for almost all analytes of interest (Table 1) when the analysis were performed in the same day (intra-day precision). The results indicate a good precision of the method and reported values similar or even better than previous publications for sludge samples $[25,26]$.
MLDs and MLQs were experimentally determined as the providing a total signal-to-noise ratio $(\mathrm{S} / \mathrm{N})$ of 3 and 10 , respectively, for each target compound. MLDs and MLQs values obtained were lower than $20 \mathrm{ng} \mathrm{g}^{-1}$ and $65 \mathrm{ng} \mathrm{g}^{-1}$, respectively, for the $72 \%$ and $70 \%$ of the target compounds in the sludge samples (Table 1). The reported values were considered acceptable for trace analysis of target analytes in a solid matrix such as sludge. Moreover, these values were similar to, or even lower than, values obtained in analogue multicomponent methods based on gas chromatography coupled to mass spectrometry (GC-MS) [12,24] and even LC-MS/MS [23,27].

The multi-residue analytical method based on UAE followed by DI in LC-MS/MS has been satisfactory validated for 44 PPCPs, with different physical-chemical properties, achieving good results of linearity, precision, accuracy, and MLDs and MLQs. 
Table 1

Lineal Range, Accuracy and Precision for Dewatered Digested Sludge.

\begin{tabular}{|c|c|c|c|c|c|c|c|c|c|}
\hline & & & & \multicolumn{2}{|l|}{ Accuracy } & \multicolumn{2}{|l|}{ Precision } & & \\
\hline & & \multicolumn{2}{|c|}{ Lineal Range } & \multicolumn{2}{|c|}{ Recovery (\%) } & \multicolumn{2}{|c|}{ Intra-day (\%RSD) } & & \\
\hline Chemical Name & ${ }^{1} \mathrm{IS}$ & $\mathrm{R}^{2}$ & Range (ng g ${ }^{-1}$ ) & $\begin{array}{l}333 \\
\left(\mathrm{ng} \mathrm{g}^{-1}\right)\end{array}$ & $\begin{array}{l}1333 \\
\left(\mathrm{ng} \mathrm{g}^{-1}\right)\end{array}$ & $\begin{array}{l}333 \\
\left(\mathrm{ng} \mathrm{g}^{-1}\right)\end{array}$ & $\begin{array}{l}1333 \\
\left(\mathrm{ng} \mathrm{g}^{-1}\right)\end{array}$ & ${ }^{2} \mathrm{MLD}\left(\mathrm{ng} \mathrm{g}^{-1}\right)$ & ${ }^{3} \mathrm{MLQ}\left(\mathrm{ng} \mathrm{g}^{-1}\right)$ \\
\hline Penicillin G & Methylparaben-d5 & 0.997 & LOQ-11760 & 122 & 115 & 5 & 8 & 8.5 & 28.3 \\
\hline Marbofloxacin & Sulfadiazine-d4 & 0.993 & LOQ-13067 & 130 & 87 & 29 & 11 & 101.8 & 339.3 \\
\hline Enrofloxacin & Enrofloxacin-d5 & 0.999 & LOQ-13333 & 60 & 70 & 17 & 2 & 52.8 & 176.0 \\
\hline Sulfadiazine & Sulfadiazine-d4 & 0.997 & LOQ-13200 & 70 & 120 & 19 & 10 & 67.5 & 225.1 \\
\hline Sulfathiazole & Sulfadiazine-d4 & 0.992 & LOQ-6667 & 112 & 83 & 17 & 19 & 15.7 & 57.5 \\
\hline Sulfadimidine & Sulfadimidine-d4 & 0.999 & LOQ-6667 & 120 & 70 & 18 & 15 & 9.3 & 31.0 \\
\hline Sulfamethizole & Sulfadimidine-d4 & 0.991 & LOQ-13333 & 102 & 93 & 12 & 17 & 2.3 & 7.7 \\
\hline Sulfamethoxazole & Sulfamethoxazole-d4 & 0.993 & LOQ-6533 & 100 & 89 & 0.8 & 21 & 0.1 & 0.3 \\
\hline Tylosin & Methylparaben-d5 & 0.996 & LOQ-11342 & 117 & 78 & 14 & 19 & 18.5 & 61.8 \\
\hline Tiamulin & Methylparaben-d5 & 0.999 & LOQ-10550 & 95 & 98 & 0.8 & 0.9 & 2.5 & 8.5 \\
\hline \multirow[t]{4}{*}{ Apramycin } & Sulfadimidine-d4 & 0.995 & LOQ-6903 & 112 & 73 & 14 & 8 & 14.5 & 48.2 \\
\hline & & & & \multicolumn{2}{|l|}{ Accuracy } & \multicolumn{2}{|l|}{ Precision } & & \\
\hline & & \multicolumn{2}{|c|}{ Lineal Range } & \multicolumn{2}{|c|}{ Recovery (\%) } & \multicolumn{2}{|c|}{ Intra-day (\%RSD) } & & \\
\hline & & & & $(\mathrm{n}=2)$ & & $(\mathrm{n}=2)$ & & & \\
\hline Chemical Name & ${ }^{1}$ IS & $\mathrm{R}^{2}$ & Range (ng g ${ }^{-1}$ ) & $\begin{array}{l}333 \\
\left(\mathrm{ng} \mathrm{g}^{-1}\right)\end{array}$ & $\begin{array}{l}1333 \\
\left(\mathrm{ng} \mathrm{g}^{-1}\right)\end{array}$ & $\begin{array}{l}333 \\
\left(\mathrm{ng} \mathrm{g}^{-1}\right)\end{array}$ & $\begin{array}{l}1333 \\
\left(\mathrm{ng} \mathrm{g}^{-1}\right)\end{array}$ & ${ }^{2} \mathrm{MLD}\left(\mathrm{ng} \mathrm{g}^{-1}\right)$ & ${ }^{3} \mathrm{MLQ}\left(\mathrm{ng} \mathrm{g}^{-1}\right)$ \\
\hline Trimethoprim & Sulfadiazine-d4 & 0.999 & LOQ-13200 & 116 & 120 & 2 & 3 & 0.5 & 1.6 \\
\hline Florfenicol & Methylparaben-d5 & 0.999 & LOQ-13309 & 107 & 80 & 9 & 6 & 15.0 & 50.9 \\
\hline Fenbendazol & Naproxen-d3 & 0.998 & LOQ-13067 & 100 & 102 & 0.02 & 2 & 8.3 & 27.6 \\
\hline Dexamethasone & Propylparaben-d7 & 0.996 & LOQ-13067 & 119 & 120 & 1 & 5 & 19.2 & 63.9 \\
\hline Progesterone & Ibuprofen-d3 & 0.999 & LOQ-13200 & 99 & 120 & 3 & 4 & 22.8 & 76.0 \\
\hline Methylparaben & Methylparaben-d4 & 0.999 & LOQ-13333 & 120 & 94 & 2 & 0.8 & 28.5 & 95.1 \\
\hline Acetaminophen & Sulfadiazine-d4 & 0.994 & LOQ-13200 & 83 & 107 & 1 & 4 & 8.8 & 29.5 \\
\hline Carbamazepine & Ethylparaben-d7 & 0.996 & LOQ-6667 & 83 & 106 & 0.3 & 0.7 & 1.4 & 4.8 \\
\hline Propranolol & Salicylic acid-d4 & 0.992 & LOQ-5845 & 110 & 77 & 5 & 7 & 17.8 & 59.4 \\
\hline Metronidazole & Sulfadiazine-d4 & 0.996 & LOQ-13333 & 112 & 108 & 6 & 1 & 4.8 & 16.1 \\
\hline \multirow[t]{4}{*}{ Ofloxacin } & Sulfadiazine-d4 & 0.998 & LOQ-13333 & 125 & 91 & 2 & 11 & 35.2 & 117.2 \\
\hline & & & & \multicolumn{2}{|l|}{ Accuracy } & \multicolumn{2}{|l|}{ Precision } & & \\
\hline & & \multicolumn{2}{|c|}{ Lineal Range } & \multicolumn{2}{|c|}{ Recovery (\%) } & \multicolumn{2}{|c|}{ Intra-day (\%RSD) } & & \\
\hline & & & & $(\mathrm{n}=2)$ & & $(\mathrm{n}=2)$ & & & \\
\hline Chemical Name & ${ }^{1}$ IS & $\mathrm{R}^{2}$ & Range (ng g ${ }^{-1}$ ) & $\begin{array}{l}333 \\
\left(\mathrm{ng} \mathrm{g}^{-1}\right)\end{array}$ & $\begin{array}{l}1333 \\
\left(\mathrm{ng} \mathrm{g}^{-1}\right)\end{array}$ & $\begin{array}{l}333 \\
\left(\mathrm{ng} \mathrm{g}^{-1}\right)\end{array}$ & $\begin{array}{l}1333 \\
\left(\mathrm{ng} \mathrm{g}^{-1}\right)\end{array}$ & ${ }^{2} \mathrm{MLD}\left(\mathrm{ng} \mathrm{g}^{-1}\right)$ & ${ }^{3} \mathrm{MLQ}\left(\mathrm{ng} \mathrm{g}^{-1}\right.$ ) \\
\hline Naproxen & Naproxen-d3 & 0.994 & LOQ-6667 & 79 & 99 & 4 & 2 & 2.6 & 8.7 \\
\hline Clarithromycin & Ethylparaben-d7 & 0.993 & LOQ-13187 & 80 & 120 & 5 & 6 & 4.0 & 13.3 \\
\hline Erythromycin & Methylparaben-d5 & 0.997 & LOQ-13067 & 101 & 103 & 11 & 0.7 & 18.5 & 61.7 \\
\hline
\end{tabular}




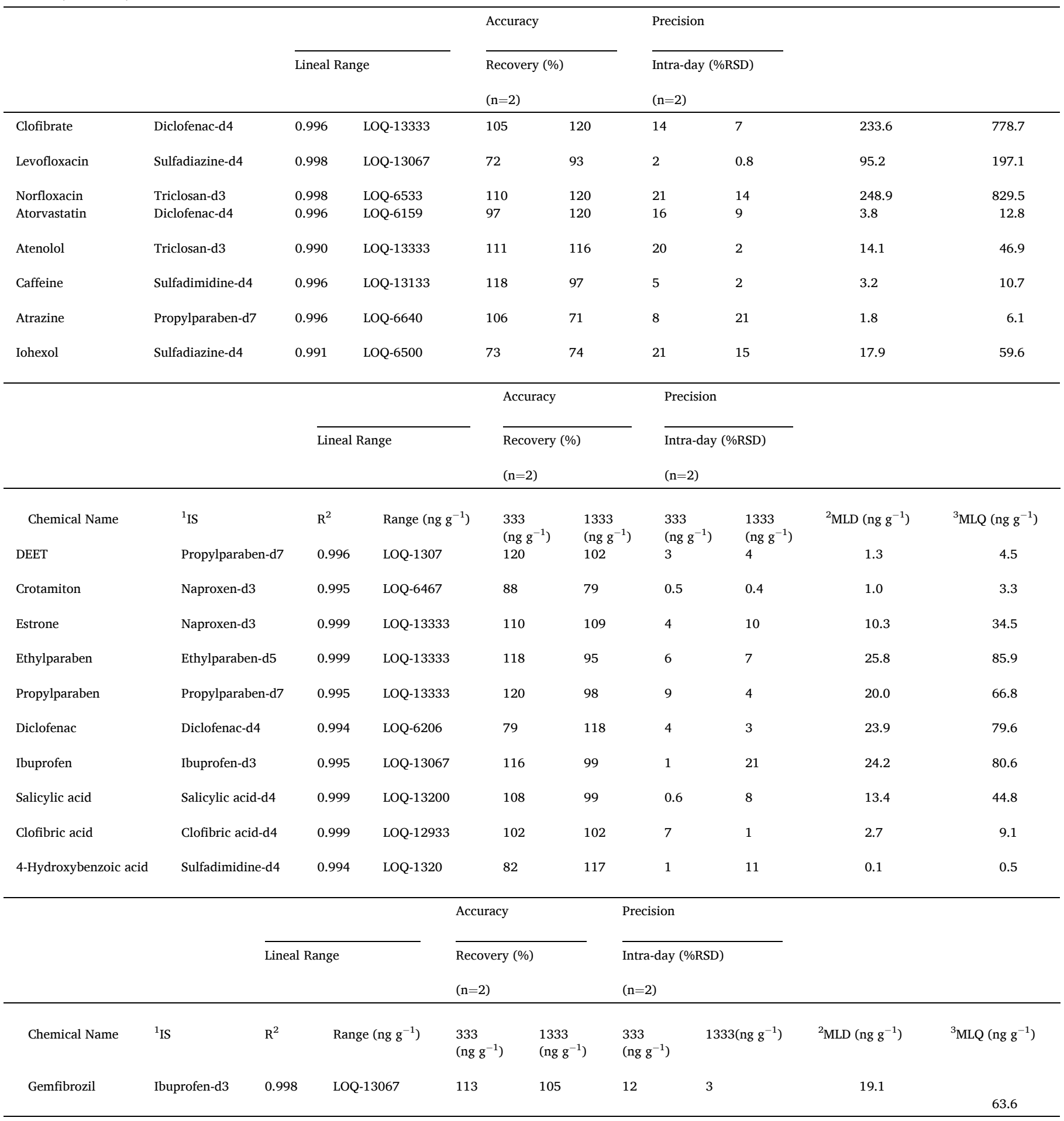

${ }^{1}$ IS: Internal Standard.

${ }^{2}$ MLD: Method Limit of Detection.

${ }^{3}$ MLQ: Method Limit of Quantification.

\subsection{DI methodology application}

Once validated, the best performing methodological option, the DI version, was successfully applied to dewatered digested sludge from the WWTP of Valladolid (Spain). Table S4 provides the average concentrations of PPCPs presented in dewatered digested sludge.

Carbamazepine, an anticonvulsant, was detected at a concentration of $36 \mathrm{ng} \mathrm{g}^{-1}$. This pharmaceutical was found in Brazil at concentrations between 10.2 and $23.8 \mathrm{ng} \mathrm{g}^{-1}$ [28]. In France, at a concentration of 39 ng $\mathrm{g}^{-1}$ [13]. Trimethoprim, a bacteriostatic antibiotic, was found at concentrations below $10 \mathrm{ng} \mathrm{g}^{-1}$. This antibiotic was detected in sludge samples at concentrations of 5 and $13 \mathrm{ng} \mathrm{g}^{-1}$ in France [29].

Analgesic and non-steroidal anti-inflammatory drugs such as salicylic acid, naproxen and diclofenac were present at levels $<$ MLQ (45, 9 and 80$) \mathrm{ng} \mathrm{g}^{-1}$, respectively. In Italy, the analgesic salicylic acid was detected in sludge samples at concentrations between 12 and $57 \mathrm{ng} \mathrm{g}^{-1}$ 
[30] and in Brazil at concentrations below $100 \mathrm{ng} \mathrm{g}^{-1}$ [31]. Naproxen, a non- steroidal anti-inflammatory drug, was also present in sludge samples at a concentration of $0.94 \mathrm{ng} \mathrm{g}^{-1}$ [30] in Italy and at a concentration of $39.8 \mathrm{ng} \mathrm{g}^{-1}$ in United Kingdom [10]. In addition, diclofenac, another non-steroidal anti-inflammatory drug very used, was found in Brazil at concentrations of 25 and $60.6 \mathrm{ng} \mathrm{g}^{-1}$ [28] and at an average concentration of $140 \mathrm{ng} \mathrm{g}^{-1}$ [13] in France.

Apramycin, a veterinary antibiotic, was found at a concentration of $172 \mathrm{ng} \mathrm{g}^{-1}$. In Greece, this compound was also detected in sludge samples at concentrations of $16.3 \mathrm{ng} \mathrm{g}^{-1}$ [25]. Propranolol, a betablocker indicated for hypertension, was detected at concentrations of $135 \mathrm{ng} \mathrm{g}^{-1}$. This compound was present in Brazil at concentrations ranging from 61.2 to $94.3 \mathrm{ng} \mathrm{g}^{-1}$ [28]. Concentrations between 82 and $849 \mathrm{ng} \mathrm{g}^{-1}$ [29] and concentrations of 46 and $54 \mathrm{ng} \mathrm{g}^{-1}$ [32] were also found in France and India, respectively.

Preservatives such as methylparaben, ethylparaben, and propylparaben, used to prevent or retard spoilage caused by chemical changes, were detected in sludge samples at concentrations between 48 and 131 $\mathrm{ng} \mathrm{g}^{-1}$. In United Kingdom, these personal care products were found at concentrations of $219 \mathrm{ng} \mathrm{g}^{-1}$, below $0.57 \mathrm{ng} \mathrm{g}^{-1}$ and below $0.72 \mathrm{ng} \mathrm{g}^{-1}$ for methylparaben, ethylparaben and propylparaben, respectively [10].

Finally, the observed concentrations (expressed at the $\mathrm{ng}^{-1}$ level) were found in the range $<$ MLQ-2,163 $\mathrm{ng} \mathrm{g}^{-1}$ for dewatered digested sludge samples. The observed results indicate contamination of sludge by PPCPs, as it is commonly used in the treatment of animal and human diseases, and the concentrations reported are similar to those in other countries.

\section{Conclusions}

In this work, three analytical methods based on the use of two different clean-up procedures (online or off-line SPE) or no clean-up stage prior to UHPLC-MS/MS determination of PPCPs in dewatered digested sludge were compared. The main conclusions are as follows:

1. A comparison of three different methodological proposals to determine 60 PPCPs in solid urban sewage sludge was carried out. In all cases, an in-situ clean-up stage, using $100.0 \mathrm{mg}$ of activated $\mathrm{Al}_{2} \mathrm{O}_{3}$, was preceded by UAE. Two fast sample pre-treatments (i.e., online SPE and DI), were tested against the conventional offline SPE. In all cases, subsequently, extracts underwent UHPLC-MS/MS, simultaneously operating in both positive and negative ESI mode.

2. The Vinj in online SPE and DI methodologies was optimized to achieve high resolution and reproducibility in chromatographic analysis. After different volumes were tested for each analytical proposal, $100 \mu \mathrm{L}$ was selected as the best performing volume for online SPE and DI, respectively.

3. Matrix-matched quantification was combined with internal standard, providing high reliability to all three proposals. Best performance was observed for the methodology consisting of UAE and DI in the LC-MS/MS with general relative recoveries between 80 and $110 \%$, repeatability expressed as $\%$ RSD below $18 \%$, MLDs under 30 $\mathrm{ng} \mathrm{g}^{-1}$ and a linearity range of up to 5 orders of magnitude for almost all the target compounds.

4. The best environmentally friendly analytical method decreased the use of fungible material (i.e., small amounts of reagents and small solvent volume) and it was satisfactorily validated for 44 PPCPs, with MLQs below $70 \mathrm{ng} \mathrm{g}^{-1}$ for many compounds of interest. In addition, this methodology applied was fast and analyst appropriate for the analysis of PPCPs in dewatered digested sludge samples.

5. This method was successfully applied to different dewatered digested sludge. An analgesic and antipyretic as acetaminophen was reported at concentrations above $1,000 \mathrm{ng} \mathrm{g}^{-1}$. PPCPs were observed in the range $<$ MLQ to $2,163 \mathrm{ng} \mathrm{g}^{-1}$ for sludge samples.

\section{Declaration of Competing Interest}

The authors declare that they have no known competing financial interests or personal relationships that could have appeared to influence the work reported in this paper.

\section{Acknowledgments}

This work was supported by the University of Valladolid (UVa) through its General Foundation (063/136391), by the Spanish Government (MINECO-CTM2015-70722-R) and by the Regional Government of Castilla y León and the EU-FEDER (CLU 2017-09, UIC 071, INFRARED2018-UVA3, and VA080G18). It was partially carried out in the Laboratory of Instrumental Techniques from the UVa. The UVa is also recognized for the postdoctoral contract held by Rebeca López Serna (2018POSTDOC UVA12).

\section{Appendix A. Supplementary data}

Supplementary data to this article can be found online at https://doi. org/10.1016/j.microc.2021.107148.

\section{References}

[1] M. Gros, M. Petrovic, D. Barceló, Analysis of emerging contaminants of municipal and industrial origin, Handb. Environ. Chem. Vol. 5 Water Pollut. 5 S1 (2008) 37-104. https://doi.org/10.1007/698_5_102.

[2] M.l. Farré, S. Pérez, L. Kantiani, D. Barceló, Fate and toxicity of emerging pollutants, their metabolites and transformation products in the aquatic environment, TrAC -, Trends Anal. Chem. 27 (11) (2008) 991-1007, https://doi. org/10.1016/j.trac.2008.09.010.

[3] A.J. Ebele, M. Abou-Elwafa Abdallah, S. Harrad, Pharmaceuticals and personal care products (PPCPs) in the freshwater aquatic environment, Emerg. Contam. 3 (1) (2017) 1-16, https://doi.org/10.1016/j.emcon.2016.12.004.

[4] K. Kümmerer, Antibiotics in the aquatic environment - A review - Part I, Chemosphere 75 (4) (2009) 417-434, https://doi.org/10.1016/j. chemosphere.2008.11.086.

[5] S. Das, N.M. Ray, J. Wan, A. Khan, T. Chakraborty, M.B. Ray, Micropollutants in Wastewater: Fate and Removal Processes, Physico-Chemical Wastewater Treat. Resour. Recover. 75 (2017) 75-107. https://doi.org/ 10.5772/65644.

[6] S. Ortiz de García, G. Pinto Pinto, P. García Encina, R. Irusta Mata, Consumption and occurrence of pharmaceutical and personal care products in the aquatic environment in Spain, Sci. Total Environ. 444 (2013) 451-465, https://doi.org/ 10.1016/j.scitotenv.2012.11.057.

[7] J. Martín, D. Camacho-Muñoz, J.L. Santos, I. Aparicio, E. Alonso, Occurrence of pharmaceutical compounds in wastewater and sludge from wastewater treatment plants: Removal and ecotoxicological impact of wastewater discharges and sludge disposal, J. Hazard. Mater. 239-240 (2012) 40-47, https://doi.org/10.1016/j. jhazmat.2012.04.068.

[8] N. Pérez-Lemus, R. López-Serna, S.I. Pérez-Elvira, E. Barrado, Analytical methodologies for the determination of pharmaceuticals and personal care products (PPCPs) in sewage sludge: A critical review, Anal. Chim. Acta. 1083 (2019) 19-40, https://doi.org/10.1016/j.aca.2019.06.044.

[9] P. Vazquez-Roig, C. Blasco, Y. Picó, Advances in the analysis of legal and illegal drugs in the aquatic environment, TrAC -, Trends Anal. Chem. 50 (2013) 65-77, https://doi.org/10.1016/j.trac.2013.04.008.

[10] B. Petrie, J. Youdan, R. Barden, B. Kasprzyk-Hordern, Multi-residue analysis of 90 emerging contaminants in liquid and solid environmental matrices by ultra-highperformance liquid chromatography tandem mass spectrometry, J. Chromatogr. A. 1431 (2016) 64-78, https://doi.org/10.1016/j.chroma.2015.12.036.

[11] S.E. Evans, P. Davies, A. Lubben, B. Kasprzyk-Hordern, Determination of chiral pharmaceuticals and illicit drugs in wastewater and sludge using microwave assisted extraction, solid-phase extraction and chiral liquid chromatography coupled with tandem mass spectrometry, Anal. Chim. Acta. 882 (2015) 112-126, https://doi.org/10.1016/j.aca.2015.03.039.

[12] N. Pérez-Lemus, R. López-Serna, S.I. Pérez-Elvira, E. Barrado, Sample pretreatment and analytical methodology for the simultaneous determination of pharmaceuticals and personal care products in sewage sludge, Chemosphere 258 (2020) 127273, https://doi.org/10.1016/j.chemosphere.2020.127273.

[13] S. Ferhi, M. Bourdat-Deschamps, J.-J. Daudin, S. Houot, S. Nélieu, Factors influencing the extraction of pharmaceuticals from sewage sludge and soil: an experimental design approach, Anal. Bioanal. Chem. 408 (22) (2016) 6153-6168, https://doi.org/10.1007/s00216-016-9725-3.

[14] M. Bourdat-Deschamps, S. Leang, N. Bernet, J.-J. Daudin, S. Nélieu, Multi-residue analysis of pharmaceuticals in aqueous environmental samples by online solidphase extraction-ultra-high-performance liquid chromatography-tandem mass spectrometry: Optimisation and matrix effects reduction by quick, easy, cheap, effective, J. Chromatogr. A. 1349 (2014) 11-23, https://doi.org/10.1016/j. chroma.2014.05.006. 
[15] S. Huntscha, H.P. Singer, C.S. McArdell, C.E. Frank, J. Hollender, Multiresidue analysis of 88 polar organic micropollutants in ground, surface and wastewater using online mixed-bed multilayer solid-phase extraction coupled to high performance liquid chromatography-tandem mass spectrometry, J. Chromatogr. A. 1268 (2012) 74-83, https://doi.org/10.1016/j.chroma.2012.10.032.

[16] L. Kovalova, H. Siegrist, H. Singer, A. Wittmer, C.S. McArdell, Hospital wastewater treatment by membrane bioreactor: Performance and efficiency for organic micropollutant elimination, Environ. Sci. Technol. 46 (3) (2012) 1536-1545, https://doi.org/10.1021/es203495d.

[17] R. López-Serna, S. Pérez, A. Ginebreda, M. Petrović, D. Barceló, Fully automated determination of 74 pharmaceuticals in environmental and waste waters by online solid phase extraction-liquid chromatography- electrospray-tandem mass spectrometry, Talanta 83 (2) (2010) 410-424, https://doi.org/10.1016/j. talanta.2010.09.046.

[18] K.T. Ng, H. Rapp-Wright, M. Egli, A. Hartmann, J.C. Steele, J.E. Sosa-Hernández, E. M. Melchor-Martínez, M. Jacobs, B. White, F. Regan, R. Parra-Saldivar, L. Couchman, R.U. Halden, L.P. Barron, High-throughput multi-residue quantification of contaminants of emerging concern in wastewaters enabled using direct injection liquid chromatography-tandem mass spectrometry, J. Hazard. Mater. 398 (2020) 122933, https://doi.org/10.1016/j.jhazmat.2020.122933.

[19] M.C. Campos-Mañas, P. Plaza-Bolaños, J.A. Sánchez-Pérez, S. Malato, A. Agüera, Fast determination of pesticides and other contaminants of emerging concern in treated wastewater using direct injection coupled to highly sensitive ultra-high performance liquid chromatography-tandem mass spectrometry, J. Chromatogr. A. 1507 (2017) 84-94, https://doi.org/10.1016/j.chroma.2017.05.053.

[20] T.S. Oliveira, M. Murphy, N. Mendola, V. Wong, D. Carlson, L. Waring, Characterization of Pharmaceuticals and Personal Care products in hospital effluent and waste water influent/effluent by direct-injection LC-MS-MS, Sci. Total Environ. 518-519 (2015) 459-478, https://doi.org/10.1016/j. scitotenv.2015.02.104.

[21] M. Argüeso-Mata, S. Bolado, J.J. Jiménez, R. López-Serna, Determination of antibiotics and other veterinary drugs in the solid phase of pig manure, Chemosphere 275 (2021) 130039, https://doi.org/10.1016/j. chemosphere.2021.130039.

[22] Commission Decision, 2002/657/EC Commission Decision of 12 August 2002 implementing Council Directive 96/23/EC concerning the performance of analytical methods and the interpretation of results, Off. J. Eur. Communities. (2002) 8-36. JOL_2002_221_R_0008_01.

[23] N. Dorival-García, A. Zafra-Gómez, F.J. Camino-Sánchez, A. Navalón, J.L. Vílchez, Analysis of quinolone antibiotic derivatives in sewage sludge samples by liquid chromatography-tandem mass spectrometry: Comparison of the efficiency of three extraction techniques, Talanta 106 (2013) 104-118, https://doi.org/10.1016/j. talanta.2012.11.080
[24] A. Luque-Muñoz, J.L. Vílchez, A. Zafra-Gómez, Multiclass method for the determination of pharmaceuticals and personal care products in compost from sewage sludge using ultrasound and salt-assisted liquid-liquid extraction followed by ultrahigh performance liquid chromatography-tandem mass spectrometr, J. Chromatogr. A. 1507 (2017) 72-83, https://doi.org/10.1016/j. chroma.2017.05.051.

[25] P. Gago-Ferrero, V. Borova, M.E. Dasenaki, N.S. Thomaidis, Simultaneous determination of 148 pharmaceuticals and illicit drugs in sewage sludge based on ultrasound-assisted extraction and liquid chromatography-tandem mass spectrometry, Anal. Chim. Acta. 407 (15) (2015) 4287-4297, https://doi.org/ 10.1007/s00216-015-8540-6.

[26] Y. Yu, L. Wu, Analysis of endocrine disrupting compounds, pharmaceuticals and personal care products in sewage sludge by gas chromatography-mass spectrometry, Talanta 89 (2012) 258-263, https://doi.org/10.1016/j. talanta.2011.12.023.

[27] M.B.R. Cerqueira, J.R. Guilherme, S.S. Caldas, M.L. Martins, R. Zanella, E. G. Primel, Evaluation of the QuEChERS method for the extraction of pharmaceuticals and personal care products from drinking-water treatment sludge with determination by UPLC-ESI-MS/MS, Chemosphere 107 (2014) 74-82, https://doi.org/10.1016/j.chemosphere.2014.03.026.

[28] M.B.R. Cerqueira, K.L. Soares, S.S. Caldas, E.G. Primel, Sample as solid support in MSPD: A new possibility for determination of pharmaceuticals, personal care and degradation products in sewage sludge, Chemosphere 211 (2018) 875-883, https://doi.org/10.1016/j.chemosphere.2018.07.165.

[29] W. Peysson, E. Vulliet, Determination of 136 pharmaceuticals and hormones in sewage sludge using quick, easy, cheap, effective, rugged and safe extraction followed by analysis with liquid chromatography-time-of-flight-mass spectrometry, J. Chromatogr. A. 1290 (2013) 46-61, https://doi.org/10.1016/j. chroma.2013.03.057.

[30] D. Rossini, L. Ciofi, C. Ancillotti, L. Checchini, M.C. Bruzzoniti, L. Rivoira, D. Fibbi, S. Orlandini, M. Del Bubba, Innovative combination of QuEChERS extraction with on-line solid-phase extract purification and pre-concentration, followed by liquid chromatography-tandem mass spectrometry for the determination of non-steroidal anti-inflammatory drugs and their metaboli, Anal. Chim. Acta. 935 (2016) 269-281, https://doi.org/10.1016/j.aca.2016.06.023.

[31] M.B.R. Cerqueira, L. Kupski, S.S. Caldas, E.G. Primel, Golden mussel shell and water in matrix solid phase dispersion: A suitable combination for the extraction of acetylsalicylic and salicylic acids from sewage sludge, Microchem. J. 148 (2019) 102-107, https://doi.org/10.1016/j.microc.2019.04.046.

[32] B. Subedi, K. Balakrishna, D.I. Joshua, K. Kannan, Mass loading and removal of pharmaceuticals and personal care products including psychoactives, antihypertensives, and antibiotics in two sewage treatment plants in southern India, Chemosphere 167 (2017) 429-437, https://doi.org/10.1016/j. chemosphere.2016.10.026. 